\title{
HARBOR AGITATION DUE TO OFFSHORE SHIP WAVES USING SWASH: A CASE STUDY OF KUMKAPI YACHT PARK, ISTANBUL
}

\author{
Cüneyt Baykal, Middle East Technical University, cbaykal@metu.edu.tr \\ Gülizar Özyurt Tarakcıoğlu, Middle East Technical University, gulizar@metu.edu.tr \\ Emrecan Işık, Middle East Technical University, emrecan.isik@metu.edu.tr
}

\section{INTRODUCTION}

This study presents the results of a numerical modeling study on the harbor agitation in case of offshore ship waves using SWASH (acronym for Simulating WAves till SHore), a numerical model developed for the simulating unsteady, non-hydrostatic, free-surface, rotational flow and transport phenomena in coastal waters as driven by waves, tides, buoyancy and wind forces (Zijlema et al. 2011). The study area is the Kumkapi Yacht Park, at the Marmara coast of Istanbul, $2.5 \mathrm{~km}$ west of the southern entrance of Bosphorus strait. The yacht park is currently used as a fishery harbor, which is severely affected by the ship waves of ferries and sea buses passing nearby almost parallel to the main breakwater of the harbor (aligned from west to east). The park is planned to berth a total of 140 yachts varying from $5 \mathrm{~m}$ to $40 \mathrm{~m}$ in length (Figure 1). For this purpose, the present harbor layout together with several alternative plans have been studied numerically to investigate agitation due to ship waves of ferries and sea buses considering the design safety requirements of ASCE (2012) for the safe mooring and berthing of yachts.

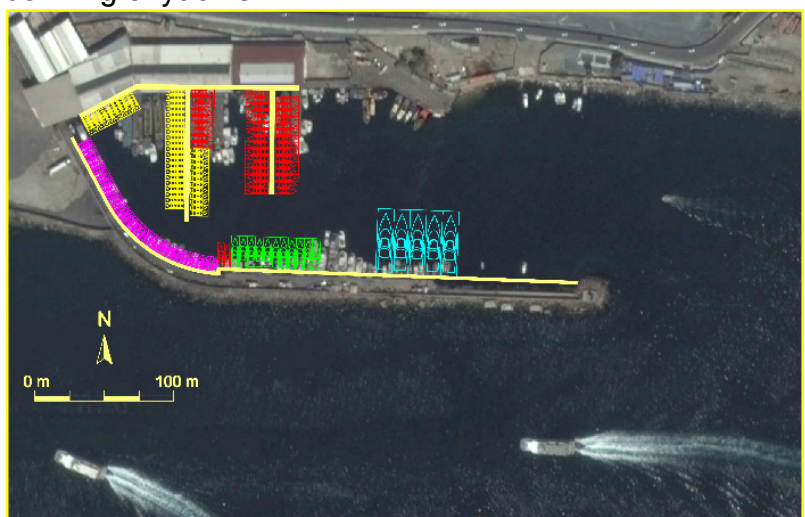

Figure 1 - Kumkapi Yacht Park layout and the ship waves due to ferries (Google Earth, 2017; Yuksel Proje, 2016).

\section{METHODOLOGY}

In the present study, the numerical model SWASH has been used to model the propagation and transformation of ship waves through the harbor. The ship waves are determined based on the physical properties of the ferries and sea buses, following the methodology given in OCDI (2009). Five different wave periods $(T=3,4,5,6$, and 7 seconds) corresponding to various speeds ( $\mathrm{Vk}=9.1$, $12.2,15.2,18.2,21.3$ knots) of the ferries have been studied. The group of ship waves are assumed to spread out in a "V" shape form, from ahead of the ship bow, making an approach angle of $35^{\circ}$ (between wave crests and main breakwater alignment). In the numerical model, the waves are assumed to be linear waves. The water depth inside the harbor is set to a minimum of $5 \mathrm{~m}$. Two types of vertical quay walls are considered in the numerical simulations; one as the impermeable vertical quay wall with the porosity equal to 0.1 and another one is the permeable wall with porosity equal to 0.7 . Three alternative layouts, based on the extension of the main breakwater in different orientations and lengths, are studied in addition to the present layout of the harbor. All these alternative layouts include a secondary floating type breakwater with a transmission coefficient of 0.6 next to the slipway. The simulations are kept as 30 minutes long and a uniform grid spacing of $2 \mathrm{~m}$ is used in the simulations. The output water surface elevations at each point inside the harbor have been analyzed and the maximum water surface amplifications are evaluated considering allowable limits for the planned yacht placement layout. Instantaneous sea surface elevations for the alternative layout $A-1$, in which the main breakwater is extended $85 \mathrm{~m}$ in 20 degrees counterclockwise with east and a floating type secondary breakwater is added, for ship waves $\mathrm{T}=4 \mathrm{~s} \quad(\mathrm{Vk}=12.2$ knots) is given in Figure 2.

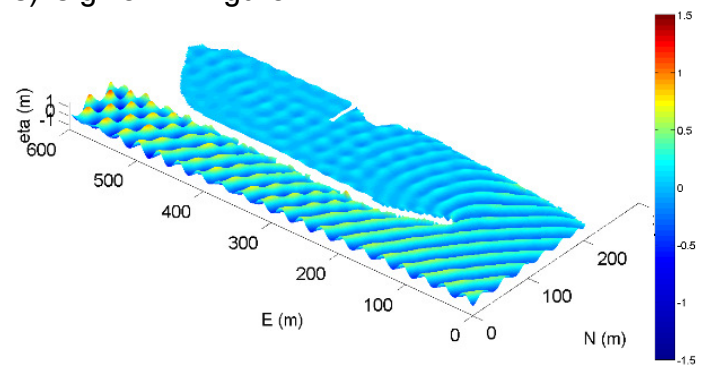

Figure 2 - Instantaneous sea surface elevations for the alternative layout $A-1$. Ship waves $T=4 \mathrm{~s}(\mathrm{Vk}=12.2 \mathrm{knots})$.

\section{CONCLUSION}

Based on the results of the numerical simulations, it is determined that, in order to satisfy the good berthing conditions inside the yacht park several improvements in layout and sea traffic is required. The main breakwater needs an extension of minimum $100 \mathrm{~m}$, while the speeds of the ferries passing nearby needs to be limited to a maximum of 10 knots and a secondary floating type breakwater of $50 \mathrm{~m}$ long is needed next to the slipway. Also, it is found that it is essential for the quay wall to be designed as a wave-absorbing perforated type with a reflection coefficient $0.5-0.6$.

\section{ACKNOWLEDGEMENTS}

The authors acknowledge the support and data provided by Yüksel Proje A.Ş.

\section{REFERENCES}

ASCE, (2012). Planning and Design Guidelines for Small Craft Harbors, 3rd Edition, ASCE Manuals and Reports on Engineering Practice No. 50.

Yüksel Proje, (2016). Kumkapı Yacht Park Wind and Wave Climate, Ship Waves, Yüksel Proje Uluslararası A.Ş., Report no: IBBB-KTP-DY-01-101-A0 and -A1. Zijlema, Stelling and Smit, (2011). SWASH: An operational public domain code for simulating wave fields and rapidly varied flows in coastal waters. Coastal Engineering, ELSEVIER, vol. 58, pp. 992-1012. 